\title{
Structured physical activity interventions as a complementary therapy for patients with inflammatory bowel disease - a scoping review and practical implications
}

\author{
Katharina G. Eckert ${ }^{1 *}$ (D), Isabelle Abbasi-Neureither ${ }^{2}$, Maximilian Köppel ${ }^{3}$ and Gerhard Huber ${ }^{4}$
}

\begin{abstract}
Background: Patients with Inflammatory Bowel Disease (IBD) also suffer from a wide range of additional disorders, which may be caused by the disease, the side effect of the medication, or a lack of physical activity (PA). This results in reduced physical and psychological wellbeing. However, as known from other chronic diseases exercise could be utilized as supportive therapy for IBD patients. Main goals of this article are (a) collecting data of the effects structured physical activity interventions have on validated clinical parameters of IBD and health related symptoms, (b) developing activity recommendations for this clientele.

Methods: A scoping review was conducted, searching for relevant articles published until May 2018, which investigated the effects of structured exercise interventions in IBD patients. The heterogeneity of the outcomes and the interventions did not support a quantitative synthesis thus, a qualitative discussion of the studies is provided.

Results: After reviewing 353 records, 13 eligible articles were identified. Five studies investigated aerobic exercise, three studies resistance exercise, three studies mind-body therapies and two studies yoga. The quality of the studies is mixed, and the duration is rather short for exercise interventions. Only few studies assessed validated IBD activity markers or inflammatory biomarkers. Nevertheless, the patients showed an increase in fitness, bone mineral density (BMD), quality of life and a decrease of IBD induced stress and anxiety. No severe adversial events were reported.

Conclusion: Even though the evidence is limited the application of exercise interventions in IBD patients can be assumed to be safe and beneficial for the patients' overall-health, and IBD specific physical and psychosocial symptoms. But there is still a high demand for more thoroughly conducted studies, focussing on important clinical outcome parameters.
\end{abstract}

Keywords: Inflammatory bowel disease, Physical activity intervention, Disease activity, Disease management

\section{Background}

Inflammatory Bowel Disease (IBD) is a chronic intestinal inflammatory illness, characterized by periods of remissions and relapses $[1,2]$. The two main types of IBD are Crohn's disease (CD) and ulcerative colitis (UC). Whereas $\mathrm{UC}$ is restricted to the large intestines and the rectum, specifically the mucosa and superficial submucosa, $C D$ is

\footnotetext{
* Correspondence: keckert@ist-hochschule.de

${ }^{1}$ IST University of Applied Sciences, Health Management and Public Health, Düsseldorf, Germany

Full list of author information is available at the end of the article
}

transmural and can affect any part of the gastrointestinal tract $[3,4]$. Until now the highest relative prevalence of IBD has been reported in European countries (UC, 505 per 100.000 persons in Norway; CD, 322 per 100.000 persons in Germany) in addition it appears be rising worldwide. While most of the industrialized nations display stable incidence rates of IBD, an increasing number of new cases can be observed in emerging countries [5].

There is still a lack of knowledge in regards to the pathophysiology and the etiology of IBD, meaning, its origin seems to be multifactorial and influenced by an

(c) The Author(s). 2019 Open Access This article is distributed under the terms of the Creative Commons Attribution 4.0 International License (http://creativecommons.org/licenses/by/4.0/), which permits unrestricted use, distribution, and reproduction in any medium, provided you give appropriate credit to the original author(s) and the source, provide a link to the Creative Commons license, and indicate if changes were made. The Creative Commons Public Domain Dedication waiver (http://creativecommons.org/publicdomain/zero/1.0/) applies to the data made available in this article, unless otherwise stated. 
abnormal immune response to gut microbes in a genetically predisposed person [6, 7]. Both diseases show symptoms like diarrhea, abdominal cramps and pain, rectal bleeding and weight loss [8]. These symptoms are often accompanied by further extraintestinal health problems [9], such as reduced BMD and osteoporosis [10-12] fatigue [13, 14], or depressive symptoms [15], a decrease in physical fitness [16-18], and an impaired overall health related quality of life (HrQoL) $[12,19,20]$ that are caused by the disease, as side effects of the medical treatments [21, 22] and a lack of PA [23, 24].

Medical treatment is often necessary throughout the patient's lifetime. Current treatments for IBD consist of medications like 5-aminosalicylic acid compounds, corticosteroids, immunosuppressants and biologics. The main cost driver is Anti-Tumor Necrosis Factor alpha (Anti-TNF $\alpha$ ) therapy, which accounts for $64 \%$ of the total costs in CD and $31 \%$ of the total costs in UC [25]. Studies have shown that the total annual direct costs of patients with IBD (i.e. medication, diagnostics, physicians and other healthcare services) range from $\$ 11$ to $\$ 28$ billion in the United States [26] and from $4.6 €$ to 5.6 billion $€$ in Europe [27]. This data implicates that IBD represents a challenge for health care systems globally. The main goal in the treatment of IBD is to reduce the quantity and the quality of the inflammation, ideally resulting in a clinical remission. Disease activity is quantified via three classes of indicators: clinical symptoms, inflammatory markers and HrQoL [28].

Since there is no cure for IBD yet, currently available drugs can only tackle its symptoms by inhibiting inflammation and delaying relapses. Despite their efficiency to relief symptoms, undesirable side effects are common [21, 22]. Therefore, many patients look for supportive and adjunctive therapies. PA has proven to be a factor in helping other chronic conditions, thus, it could be a feasible approach for IBD patients [29]. However, not enough is known about the impact of structured PA interventions on the clinical course of IBD or side effects associated with the disease and its treatments [30]. Hence, these are the main goals of this paper:

a) Collecting data and giving evidence about the effects of structured physical exercise interventions on inflammatory biomarkers, clinical activity metrics and HrQoL as directly with the disease associated primary outcomes, and on physical and psychosocial functions (e.g. muscle performance, BMD, cardiorespiratory fitness, fatigue) as secondary outcomes.

b) Developing PA recommendations, which are specific for IBD patients.

\section{Methods}

\section{Search strategy}

In May 2018 a literature search was conducted using the databases of PubMed, Cinhal and Web of Science for relevant abstracts and articles on IBD and PA interventions. The search terms included: exercise, physical activity, PA, motor activity, resistance training, strength training, endurance training, aerobic, sport for the semantic space of exercise. These terms were paired with inflammatory bowel disease, IBD, Crohn's disease, $\mathrm{CD}$, ulcerative colitis, UC (using AND as operator). By screening Google Scholar and the reference lists of the included studies, overlooked studies were added. All identified titles and abstracts were assessed for eligibility by two reviewers independently (KE and MK).

\section{Study selection}

The following criteria determined which references were included: Only adults ( $\geq 18$ years) diagnosed either with CD or UC. Only full-text articles written in English were selected. Only longitudinal study designs with PA interventions were included. Studies were not limited with regards to type of PA. All publication years were included in the search. Studies on Irritable Bowel Syndrome were excluded.

\section{Data extraction}

Included full texts were assessed by $\mathrm{KE}$ and $\mathrm{GH}$ independently. The heterogeneity of the conducted interventions, the inconsistency in outcome measures and the complex nature of IBD (phenotype, location, disease activity, medication and disease related symptoms) made a meta-analytical synthesis of the outcomes implausible, thus a qualitative approach was preferred to present the current evidence. All eligible studies were classified according to 2011 Oxford Centre for Evidence-Based Medicine (OCEBM) levels of evidence (first column: Does this intervention help?) [31]. The review was structured according to the Preferred Reporting Items for Systematic Reviews and Meta-Analyses (the PRISMA statement) [32].

\section{Results}

A total of $n=353$ articles were identified. After excluding duplicates and scanning titles as well as abstracts, $n=45$ articles were retrieved and examined. Another $n=6$ articles were added after scanning the references of chosen articles. These $n=51$ articles were eligible for full text screening, resulting in further exclusion of $n=41$ articles. Although two abstracts and one letter to the editor were excluded after title and abstract screening, we included them after all due to their relevance. Thus, 13 articles were used for the qualitative analysis (Fig. 1). 


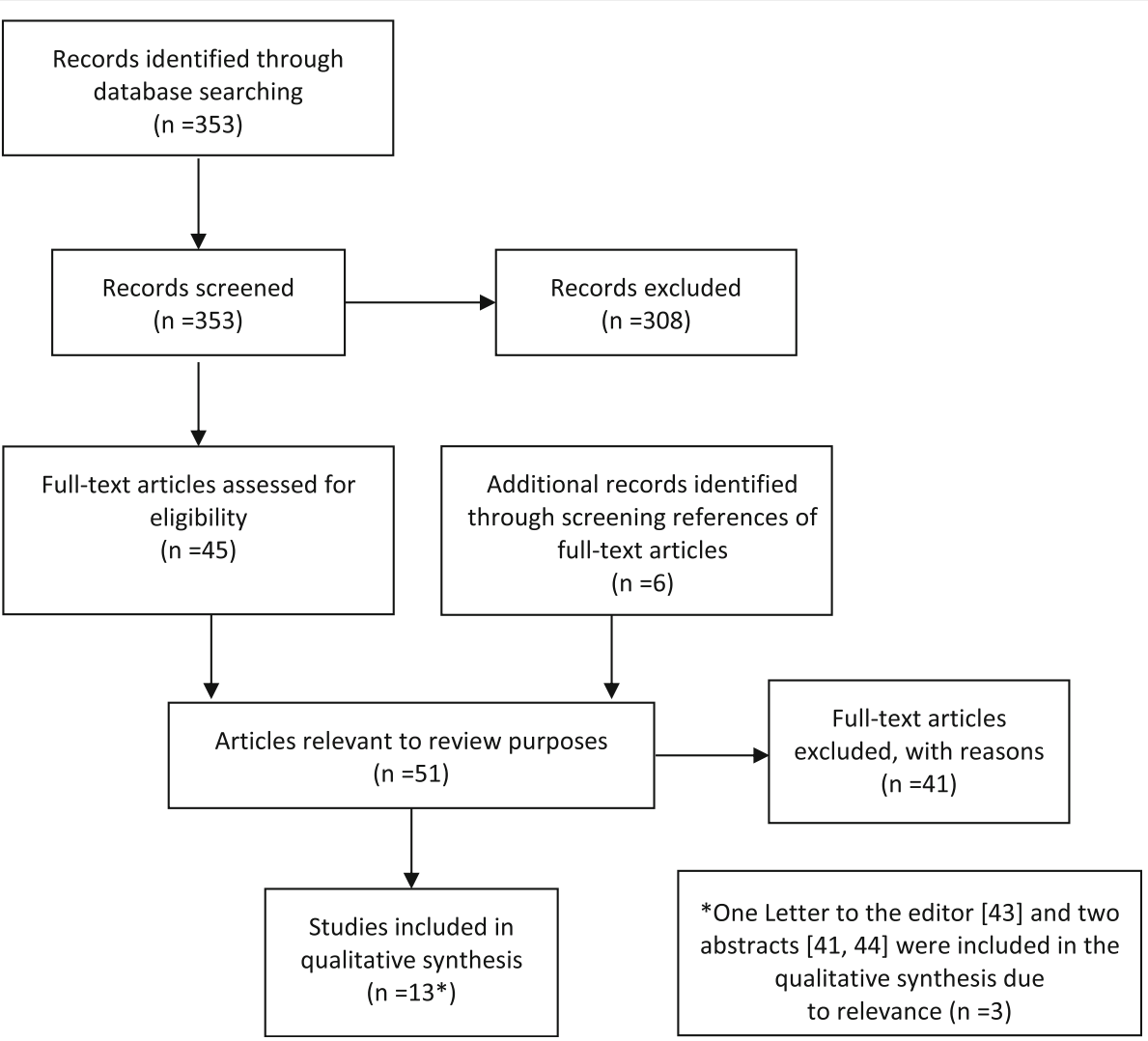

Fig. 1 Flow diagram of literature search and study selection

Reasons for the exclusion of articles are presented in Table 1.

\section{Characteristics of the studies}

Thirteen studies were included in this review. Seven studies were randomized controlled trials (RCT) [7, 30, 33-37] and six studies used a quasi-experimental design [38-43].

Selected studies were conducted between the years 1999 and 2017, with $n=6$ published within the last 4 years. The sample sizes vary from 6 to 107 subjects. Five of the studies included patients with $\mathrm{CD}$ only two investigated patients with UC and six studies incorporated both diseases. All study participants were either in

Table 1 Reasons for exclusion of full-text articles

\begin{tabular}{ll}
\hline Reason for exclusion & Number of articles excluded \\
\hline No PA intervention & $n=29$ \\
No IBD patients & $n=5$ \\
Study protocol & $n=1$ \\
Use of same study sample & $n=2$ \\
Reviews / no Interventions & $n=4$ \\
$\begin{array}{l}\text { Total number of articles excluded after } \\
\text { full text screening }\end{array}$ & $\mathbf{n = 4 1}$ \\
\hline
\end{tabular}

remission or had a mild to moderate disease activity at the time of intervention. With regards to methodological limitations, the study results are presented descriptively in accordance with their primary results. Statistical parameters are listed if they were provided. (Table 2).

\section{Findings by type of exercise intervention Cardiovascular training}

Five studies reported the effects of a cardiovascular training on diverse health outcomes. D'Inca and colleagues found neither statistically significant changes in the assessed gastrointestinal health parameters nor significant changes in disease activity after 1 hour of cycle ergometer exercise [38]. On the other hand, Loudon et al. [39] and $\mathrm{Ng}$ et al. [30] observed positive effects on stress parameters (IBD Stress Index) $p<.001$ [39] and $p<.05$ [30]), HrQoL (IBD Questionnaire (IBDQ) $p=.01$ [39] and $\mathrm{p}<.05$ [30]) and cardiorespiratory fitness $\left(\mathrm{VO}_{2} \max p<.01[39]\right)$ in people with $\mathrm{CD}$, involving a walking intervention taking place once a week for 3 months. A supervised outdoor running program, three times a week for 10 weeks, resulted in significant improvements in the social dimension of HrQoL (IBDQ social dimension $p=.03$ ) but showed no changes in disease activity (Crohn's Disease Activity Index (CDAI) 
Eckert et al. BMC Gastroenterology

(2019) 19:115

Page 4 of 12

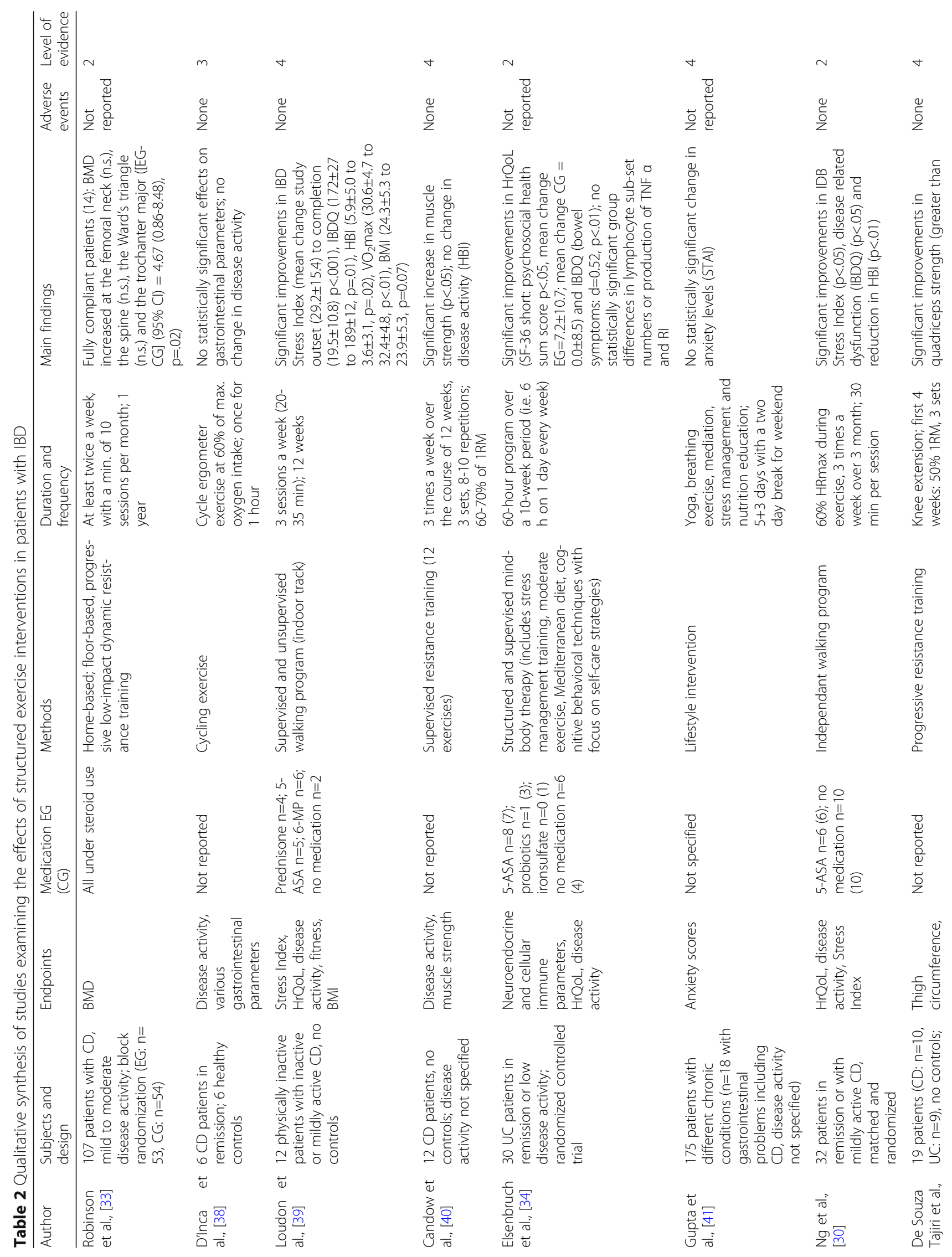


Eckert et al. BMC Gastroenterology

(2019) 19:115

Page 5 of 12

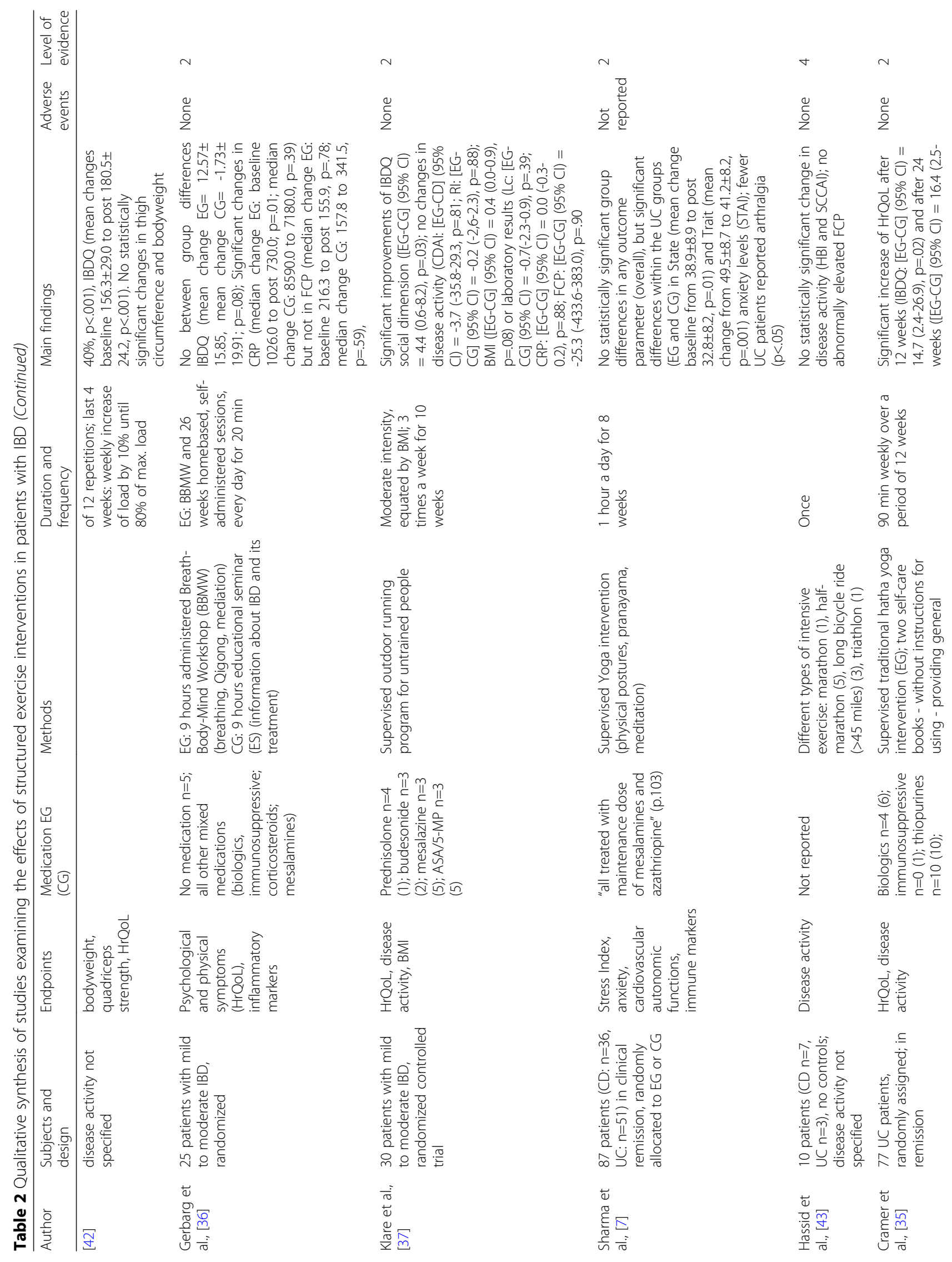




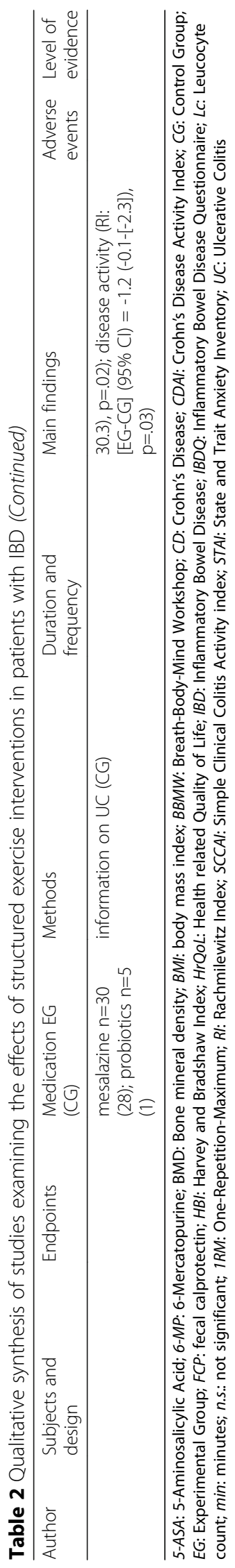


$p=.81$; Rachmilewitz Index (RI) $p=.88$ ) or laboratory parameters (Leucocyte count (Lc) $p=.39$, C-reactive protein (CRP) $\mathrm{p}=.88$, fecal calprotectin $(\mathrm{FCP}) p=.90$ ) [36]. Hassid et al. examined the effects of different types of high voluminous sport activities (marathon, halfmarathon, long bicycle rides and triathlon) on disease activity (Harvey and Bradshaw Index (HBI); Simple Clinical Colitis Activity Index (SCCAI)) in 17 mixed IBD patients. As result, no significant changes or harmful effects were discovered instantly and a week after the exercise [43].

\section{Strength training}

In three studies, the patients participated strength training, with two supervised interventions were executed on weightlifting machines [40, 42]. With only one study assessing a disease activity index [40]. Candow and colleagues chose a 12-week intervention on 12 different training machines with constant intensity and number of repetitions [40]. The participants in De Souza Tajiris et al. study performed an isolated, progressive training involving only the quadriceps muscle [42]. Both found a significant increase in muscle strength $(p<.05$ [40], $p<.001$ [42]). Nevertheless, the progressive training protocol leads to a significant improvement in patients' HrQoL (IBDQ $\mathrm{p}<.001$ [42]), but failed to decrease the disease activity (HBI) significantly [40]. In one study, a home- and floor-based low impact dynamic resistance training was conducted. The intervention lasted for over 1 year and had improvements in BMD as primary outcome. Fully compliant patients showed a significant increase in BMD for the trochanter major $(p=.02)$. All other assessed anatomical structures showed no statistically significant increase in BMD [33].

\section{Yoga}

Cramer et al. randomly assigned 77 UC patients to either a 12-weeks lasting traditional Hatha yoga group or an inactive control group. Participants of the yoga group showed significantly higher HrQoL scores (IBDQ $p=.02$ ) and lower disease activity (RI $p=.03$ ) 24 weeks after the intervention [37]. Sharma et al. carried out a supervised yoga intervention over the course of 8 weeks with patients in remission. While patients with UC showed slightly improved anxiety scores (STAI: State $(p=.01)$ and Trait $(p=.001)$ anxiety levels) and fewer arthralgia $(p<.05)$, patients with $\mathrm{CD}$ displayed no changes. Also no impact on cardiovascular autonomic functions or immune markers (Lc, Serum eosinophilic cationic protein (ECP)) was observed [7].

\section{Lifestyle intervention - mixed methods}

In three studies various mind-body therapies were conducted, including e.g. yoga, meditation, stress management, nutrition, relaxation techniques, education about the disease and cognitive behavioral techniques. Gupta et al. found no effects on anxiety levels, disease activity or inflammatory markers while Gerbarg and colleagues detected significant improvements in CRP for the EG $(p=.01)$ but not for the CG $(p=.39)[36,41]$. In a structured and supervised mind-body therapy over a 10-week period ( $6 \mathrm{~h}$ on 1 day per week), higher HrQoL scores for the EG were observed (SF-36 psychosocial health sum $p<.05$ and IBDQ $p<.01$ ), but no effects on disease activity (RI) or neuroendocrine and cellular immune measures (Lc,TNF $\alpha$ ) [34].

\section{Discussion}

The current review investigated the effects of structured PA interventions on inflammatory biomarkers, clinical activity indices and HrQoL as directly with the disease associated primary outcomes and of physical and psychosocial functions in patients as secondary outcomes. It follows a presentation of the biological, physical and psychosocial effects. Additionally, the known effects and mechanisms of exercise in other clinical populations [29, 44] will be displayed and their potential for IBD patients discussed.

\section{Biologic rationale for benefits of PA interventions in IBDs a) Inflammatory biomarkers}

The conducted exercise trials report only minor changes in laboratory markers $[7,34,36,37]$. Three of the included studies investigated the effects of exercise on inflammatory biomarkers like FCP, CRP, Lc and TNF $\alpha$, with merely one study showing a significant reduction in CRP [36]. Despite the importance of TNF $\alpha$ in IBD, only one study explored this parameter; however, no significant effect on the TNF $\alpha$ basal levels were observed within the treatment group, that conducted mind-body therapy [34]. To the best of our knowledge, only one additional study has investigated the relationship of PA and inflammation in IBD patients [54]. Plöger et al. reported a positive association of exercise and increased levels of Interleukin 6 (IL-6) in children with IBD. However this study was not included in this review, since it is limited to studies conducted in adults.

The anti-inflammatory effect of PA is well investigated in Type 2 Diabetes and Cardiovascular diseases [45]. It can be attributed to the release of cytokines, such as IL6 , which affects the systemic inflammation via crosstalk on TNF $\alpha[46,47]$. Observations of anti-inflammatory pathways were made in murine models and have also been confirmed in exercise studies with humans, involving strength training [48] and strenuous aerobic exercise [49]. Even though the evidence provides a framework for similar effects in IBD patients, it is not possible to draw clear conclusions from the analyzed studies. However, 
the evidence with regards to the beneficial effects of moderate PA on the immune system seems promising $[55,56]$. This is particularly important since TNF $\alpha$ is a major pathological marker in IBD [50], while the serum level of TNF $\alpha$ correlates with the clinical activity of CD and UC [51].

The characteristics of the exercise stimulus, such as frequency, intensity, time (duration) and type (FITT-Criteria) [52], have a direct impact on the release of the anti-inflammatory cytokines. The IL-6 plasma concentration increases almost exponentially in relation to the duration of exercise. For instance, $30 \mathrm{~min}$ of endurance training at $75 \% \mathrm{VO}_{2}$ max increases the IL- 6 plasma concentration by five times. Further investigations have shown that the type of exercise as well as the amount of recruited muscle mass determine the extent of IL- 6 release [53]. PA involving several large muscle groups, such as brisk walking or rowing, has shown the highest plasma IL-6 increase [45]. Although other mediators, like adrenaline, that blunts the appearance of TNF $\alpha$, may contribute to the anti-inflammatory effect of exercise, the findings from Pedersen and colleagues emphasize that muscle derived IL-6 is the true antiinflammatory exercise factor [53].

\section{Disease activity}

Eight out of the 13 included studies assessed changes in disease activity by using validated metrics $[30,34,35$, 37-40, 43] (HBI $n=4$, CDAI $n=2$; RI $\mathrm{n}=2$, SCCAI $n=$ $1)$. In three of these studies, positive effects on the disease activity indices were found. The five remaining studies found neither positive nor negative effects of the interventions on clinical disease activity. Given that the studies did not find any increase of the disease activity, exercise can be seen as feasible and safe for this population. To further investigate potential mechanisms and effects of exercise on the disease activity, it might be useful to look into the single disease activity parameters of the assessment tools, considering a physiological rationale.

\section{Health benefits of PA interventions in IBD \\ a) Physical effects}

The included interventional studies barely report physical effects thus estimations of the cardiovascular, muscular, and bony adaptions remain uncertain and had to be derived from studies conducted in other clinical populations [29]. Nevertheless, the few studies that investigated the effect of the interventions on physical parameters show an increase in $\mathrm{VO}_{2} \max$ [39], muscle strength [40, 42] and BMD [33].

An increased risk to develop osteopenia or osteoporosis, is very common in IBD. Approximately $40 \%$ of all IBD patients have developed osteoporosis [10-12].
Nonetheless, the causes of low BMD are multifactoral in IBD patients, an increase in pro-inflammatory cytokines disturbes the bone remodelling process by increasing osteoclastic and inhibiting osteoblastic functions [10, 57]. Most IBD patients present a decreased muscle mass in comparison to their healthy controls [16], which can be attributed to the catabolic effect of cytokines [58, 59], physical inactivity [23, 24], malnutrition and malabsorption [60] as well as the use of corticosteroids [17, 61]. IBD patients also seem to suffer from reduced cardiorespiratory fitness, with a direct link to low PA levels [16, 18]. This is of significance, since reduced physical fitness levels are correlated to increased systemic inflammation [47].

Muscle strength, $\mathrm{BMD}$ as well as $\mathrm{VO}_{2}$ max are essential predictors of all-cause mortality in a wide range of populations [62], thus, these can be seen as surrogate parameters for several health parameters, such as physical functioning and autonomy.

\section{b) Psychological effects}

Although fatigue affects nearly $50 \%$ of patients in clinical remission and over $80 \%$ with active disease [65], none of the included studies assessed it. Fatigue, an intense tiredness with reduced energy levels and feelings of exhaustion [63], is considered to be the most burdensome symptom in IBD patients [14, 64]. As known from research of other chronically ill people, PA can effectively address the symptoms of fatigue [65-67]. Fatigue contributes to a loss in muscle mass due to the lack of PA $[23,24,68]$ especially in a population with an existing muscular disadvantaged [16]. Hitherto, the etiology of fatigue cannot be explained [65], though, an assessment of Cancer Related Fatigue (CRF) shows, that the amount of circulating pro-inflammatory blood cytokines are strongly associated with the severity of CRF [69-71]. Although studies involving IBD patients do not investigate fatigue, studies with CRF patients seem to include rather promising information [71], meaning the modes of action PA exhibits on CRF may be beneficial for IBD patients $[65,67]$.

Stress and anxiety are typically perceived by IBD patients and can trigger relapses [72]. One of the two studies assessed anxiety showed significant reductions in both, the State and the Trait sum scores [7]. In two out of three studies, the aerobic exercise groups showed a significant reduction in stress [30,39]. Excercise may be a useful treatment for anxiety and stress. Nevertheless the relative paucity of evidence leaves the question open whether a direct mechanism for exercise to reduce anxiey exists [73]. Possible explanations of reduced anxiety levels after PA interventions can be attributed to improved health-related self-efficacy [74] and perceived control [75] through fitness gains. Both are known to 
positively influence adherence to treatment and medication [76]. These potential effects of PA are essential for all chronically ill patients, and thus for people with IBD.

Having a chronic disease that affects bowel function can impact many aspects of life beyond the medical symptoms, e.g. social life and the patients' HrQoL. The ultimate target of therapy for IBD is to alter the course of the disease and thus improve the quality of life. The HrQoL of IBD patients is determined by the markers of the disease activity, such as increased clinical activity markers, number of relapses, working disabilities and hospitalization [77]. Research shows consistent associations between moderate PA with increased HrQoL not only for healthy individuals [78] but also for chronically ill people $[79,80]$. Six of the studies report similar effects on the general HrQoL as well as on the HrQoLsubscales for structured PA interventions in IBD [30, 34, $35,37,39,42]$. A recent cross-sectional study found that engaging in higher quantities of walking in a moderate intensity (equivalent to recommended activity guidelines) is independently associated with increased physical HrQoL in people with IBD [81]. PA may be an efficient non-pharmacological supportive treatment in IBD, and will increase patient's HrQoL, but lack of data from rigorous, methodologically sound RCTs precludes any definitive conclusions about its effectiveness.

In summary structured PA interventions may have the potential to break the cycle of physical inactivity, muscular deconditioning, poor fitness and decreased BMD, leading to reduced fatigue and anxiety, which ultimately improve stress, disease management abilities and HrQoL. Besides these effects it is possible that regular PA and exercise have a beneficial antiinflammatory impact on immunologic biomarkers (e.g. CRP, TNF $\alpha$ ) in IBD. In any event, exercise can improve the physical and psychological health of the patients.

Most of the existing studies have significant methodological limitations. In detail we acknowledge the following: As known, the recruitment of patients for exercise studies via advertisement, e.g., newspaper, radio, flyer or email, results in an ascertainment bias, i.e. only those who already have a high motivation to exercise will participate. Due to the recruitment pathways it is possible to only reach certain populations, which can skew the distribution of socioeconomic and educational variables. The studies were limited to IBD patients with mild to moderate disease severity, which narrows the applicability of the results. In addition, the initial PA level was not assessed. Changes in PA levels during the study are a crucial aspect since they impact the benefits from exercise. None of the studies conducted an a priori power analysis, thus all studies, except of Sharma et al. [7] and Cramer et al. [35], had very small sample sizes that lead to uncertain parameter estimates. Merely one study reported blinding of the control group. Since all studies reported every measured outcome and results do not seem to support the interventions, a publication bias seems unlikely, but we acknowledge that the absence of a research librarian during the reviewing process may limit our results. Because of the limited data available, mechanisms of exercise used for IBD can only be hypothesized at this time (Fig. 2).

\section{Conclusion}

As stated by Pedersen et al., PA '...represents a natural, strong anti-inflammatory and metabolic-improving strategy with minor side effects ... [45] p.607]'. The benefits of structured PA interventions on IBD symptoms have

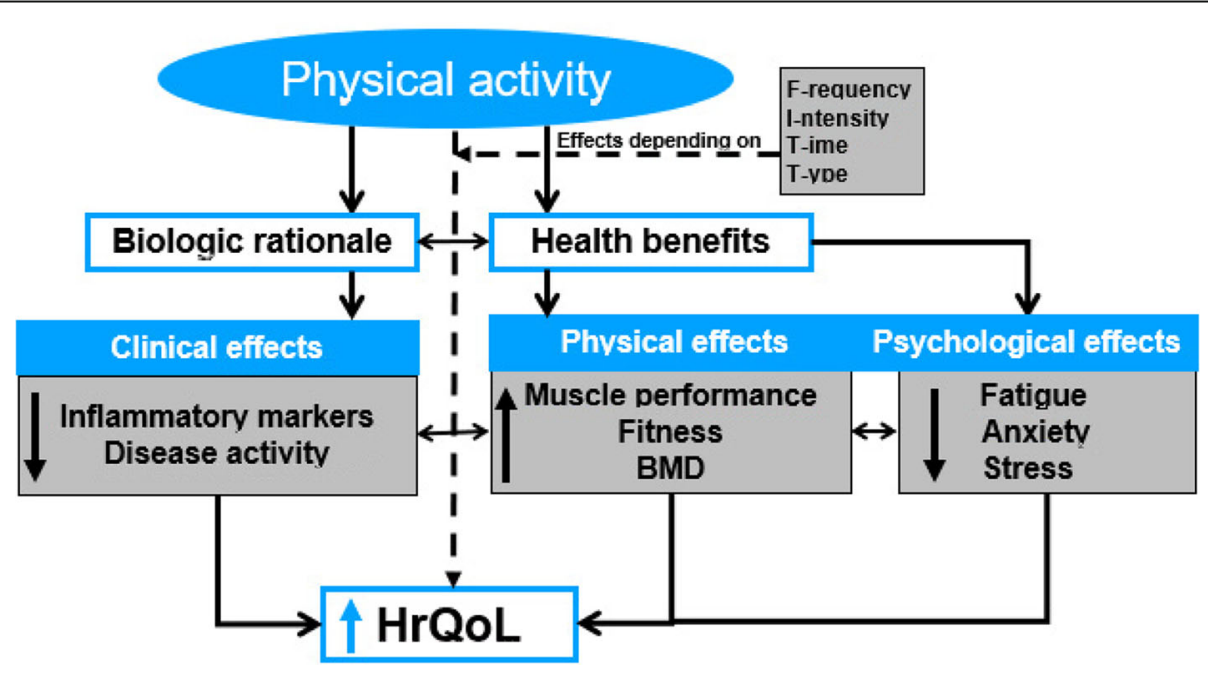

Fig. 2 Possible clinical, physical and psychological effects of PA in IB 
not been sufficiently investigated up to now [82], even though they are evident in other chronic diseases [29]. Nevertheless, low to moderate PA seems safe for patients with mild to moderate IBD. Only two out of 13 studies reported slightly negative effects immediately after the PA intervention, though they did not persist $[43,35]$.

We assume, that the little impact of the interventions on health parameters might have been caused by the heterogenous training methods and chosen intensities. Further research upon the most appropriate type of exercise is required.

Conclusively we deviate - based on this review and derived from existing evidence of morphologic adaptations and psychosocial effects of PA in other populations - PA recommendations for IBD patients along with methodological recommendations for upcoming studies:

- Type and volume of exercise must be sufficient to stimulate anti-inflammatory effects. Research has shown, that the anti-inflammatory output of exercise depends on the FITT-Criteria [45] as well as the amount of recruited muscle mass [53]. In order to assist clinicians to advise patients better and improve the design of future exercise studies, a representation of recommended FITT criteria, has been provided in Table 3.

- The maintenance of an active lifestyle is the main goal of all exercise interventions. Thus, future studies need to implement psychological techniques to enhance motivation, self-regulation and selfreflection, in order to enable patients implement PA for their individual disease management [83].

- An agreement in standardized assessment instruments including the most important health

Table 3 Physical activity recommendations for patients with mild-to-moderate IBD

\begin{tabular}{|c|c|}
\hline FITT-Criteria & The patient should.... \\
\hline F-requency & $\begin{array}{l}\text {...engage in moderate PA at least three times a week, even } \\
\text { better five times a week. }\end{array}$ \\
\hline I-ntensity & $\begin{array}{l}\text {... choose an activity which increases the energy } \\
\text { expenditure by at least a factor of three or four, as it is the } \\
\text { case for brisk walking. For exercise control via heart rate } \\
(\mathrm{HR}) \text {, the intensity of the exercise should be between } 60 \text { - } \\
80 \% \text { of the maximum HR. Bear in mind: moderate intensity } \\
\text { is key in order to improve inflammation. }\end{array}$ \\
\hline T-ime & $\begin{array}{l}\ldots \text { exercise for at least } 30 \text { minutes per day (more is even } \\
\text { better, if tolerated). }\end{array}$ \\
\hline T-ype & $\begin{array}{l}\text {... engage in an enjoyable activity, to increase the } \\
\text { probability to maintain this behavior. Exercising in groups } \\
\text { can increase the motivation. A mixture of endurance and } \\
\text { resistance exercise is favorable, because it avoids unilateral } \\
\text { training and emphasizes the use of all big muscle groups. } \\
\text {... increase the amount of leisure time PA. "Walk before you } \\
\text { run". }\end{array}$ \\
\hline
\end{tabular}

outcomes in IBD would be necessary for the quantitative synthesis of future studies [28, 84]. The interventions as well as outcome assessments should be multidimensional, i.e. the combination of diseasespecific clinical markers with physiological and psychological parameters.

- Future investigations should assess quality of life as it is an important aspect of medical decision-making and a major goal of therapy.

- Because of the cyclical nature of IBD and the individuality of the disease patterns, it is difficult to conduct standardized large-scale RCTs. To counteract this methodological obstacle the application of systematic N-of-1-trials can be helpful [85].

\section{Abbreviations}

Anti-TNF a: Anti-Tumor Necrosis Factor alpha; BMD: Bone mineral density; BMI: Body mass index; CD: Crohn's Disease; CG: Control Group; CRF: Cancer Related Fatigue; CRP: C-reactive protein; ECP: Serum eosinophilic cationic protein; EG: Experimental Group; FCP: Fecal calprotectin; HR: Heart rate; HrQoL: Health related Quality of Life; IBD: Stress Index: Inflammatory Bowel Disease Stress Index; IBD: Inflammatory Bowel Disease; IBDQ: Inflammatory Bowel Disease Questionnaire; IL-6: Interleukin 6; Lc: Leucocyte count; min: minutes; n.s: not significant; OCEBM: Oxford Center for Evidence-Based Medicine; PA: Physical activity; PRISMA: Preferred Reporting Items for Systematic Reviews and Meta-Analyses; RCT: Randomized Controlled Trail; RI: Rachmilewitz Index; SCCAI: Simple Clinical Colitis Activity Index; STAI: State and Trait Anxiety Levels; TNF a: Tumor Necrosis Factor a; UC: Ulcerative colitis

\section{Acknowledgements}

The authors would like to thank B D-S for her support in language editing.

\section{Authors' contributions}

KE and MK searched and selected the trials. KE and GH extracted and analyzed the data. KE, MK and GH drafted the manuscript. IA-N critically reviewed the manuscript and gave medical feedback. All authors interpreted the existing evidence and read and approved the final manuscript.

\section{Funding}

No funding. Not applicable.

Availability of data and materials

Not applicable.

Ethics approval and consent to participate

Not applicable.

Consent for publication

Not applicable.

\section{Competing interests}

The authors declare that they have no competing interests.

\section{Author details}

'IST University of Applied Sciences, Health Management and Public Health, Düsseldorf, Germany. ${ }^{2}$ Practice for Internal Medicine and Gastroenterology, Heidelberg, Germany. ${ }^{3}$ Penn State University, Department of Public Health Science, Hershey, USA. ${ }^{4}$ University of Heidelberg, Institute of sport and sportscience, Heidelberg, Germany.

Received: 25 January 2019 Accepted: 24 June 2019

Published online: 02 July 2019

\section{References}

1. Fiocchi C. Inflammatory bowel disease: etiology and pathogenesis. Gastroenterology. 1998;115(1):182-205. 
2. Bilski J, Mazur-Bialy Al, Wierdak M, Brzozowski T. The impact of physical activity and nutrition on inflammatory bowel disease: the potential role of cross talk between adipose tissue and skeletal muscle. J physiol pharmacol. 2013;64(2):143-55.

3. Burisch J, Munkholm P. The epidemiology of inflammatory bowel disease. Scand J Gastroenterol. 2015:50(8):942-51.

4. Wang $Q$, Xu K-Q, Qin X-R, Wang X-Y. Association between physical activity and inflammatory bowel disease risk: A meta-analysis. Dig Liver Dis. 2016; 48(12):1425-31.

5. Ng SC, Shi HY, Hamidi N, Underwood FE, Tang W, Benchimol El, Panaccione R, Ghosh S, JCY W, FKL C. Worldwide incidence and prevalence of inflammatory bowel disease in the 21st century: a systematic review of population-based studies. The Lancet. 2017;390(10114):2769-78.

6. Abraham C, Cho JH. Mechanisms of disease. N Engl J Med. 2009;361:2066-78.

7. Sharma P, Poojary G, Dwivedi SN, Deepak KK. Effect of yoga-based intervention in patients with inflammatory bowel disease. Int J Yoga Therap. 2015;25(1):101-12

8. Elsherif $Y$, Alexakis C, Mendall M. Determinants of weight loss prior to diagnosis in inflammatory bowel disease: a retrospective observational study. Gastroenterol Res Pract. 2014;2014.

9. Levine JS, Burakoff R: Extraintestinal manifestations of inflammatory bowel disease. Gastroenterol Hepatol 2011, 7(4):235.

10. Lee N, Radford-Smith G, Taaffe DR. Bone loss in Crohn's disease: exercise as a potential countermeasure. Inflamm Bowel Dis. 2005;11(12):1108-18.

11. Mauro M, Armstrong D. Evaluation of densitometric bone-muscle relationships in Crohn's disease. Bone. 2007;40(6):1610-4.

12. Perez Pérez CA. Prescription of physical exercise in Crohn's disease. J Crohn's Colitis. 2009;3(4):225-31.

13. van Langenberg DR, Gibson PR. Factors associated with physical and cognitive fatigue in patients with Crohn's disease: a cross-sectional and longitudinal study. Inflamm Bowel Dis. 2013;20(1):115-25.

14. Hindryckx P, Laukens D, D'Amico F, Danese S: Unmet needs in IBD: the case of fatigue. Clin Rev Allergy Immunol 2017:1-11.

15. Fuller-Thomson E, Sulman J: Depression and inflammatory bowel disease: findings from two nationally representative Canadian surveys. Inflamm Bowel Dis 2006, 12(8):697-707.

16. Zaltman C, Braulio VB, Outeiral R, Nunes T, Natividade de Castro CL: Lower extremity mobility limitation and impaired muscle function in women with ulcerative colitis. J Crohn's Colitis 2014, 8(6):529-535.

17. Wiroth J-B, Filippi J, Schneider SM, Al-Jaouni R, Horvais N, Gavarry O, Bermon S, Hébuterne X. Muscle performance in patients with Crohn's disease in clinical remission. Inflamm Bowel Dis. 2005;11(3):296-303.

18. Melinder C, Hiyoshi A, Hussein O, Halfvarson J, Ekbom A, Montgomery S. Physical fitness in adolescence and subsequent inflammatory bowel disease risk. Clin Transl Gastroenterol. 2015;6(11):e121.

19. Guthrie E, Jackson J, Shaffer J, Thompson D, Tomenson B, Creed F. Psychological disorder and severity of inflammatory bowel disease predict health-related quality of life in ulcerative colitis and Crohn's disease. Am J Gastroenterol. 2002;97(8):1994.

20. Kalafateli M, Triantos C, Theocharis G, Giannakopoulou D, Koutroumpakis E, Chronis A, Sapountzis A, Margaritis V, Thomopoulos K, Nikolopoulou V. Health-related quality of life in patients with inflammatory bowel disease: a single-center experience. Ann Gastroenterol. 2013;26(3):243.

21. Baumgart DC, Sandborn WJ. Inflammatory bowel disease: clinical aspects and established and evolving therapies. The Lancet. 2007:369(9573):1641-57.

22. Duijvestein M, Battat R, Casteele NV, D'Haens GR, Sandborn WJ, Khanna R, Jairath $\mathrm{V}$, Feagan BG: Novel therapies and treatment strategies for patients with inflammatory bowel disease. Curr Treat Options Gastroenterol 2018, 16(1):129-146.

23. Shephard RJ. The case for increased physical activity in chronic inflammatory bowel disease: a brief review. Int J Sports Med. 2016;37(07): 505-15.

24. Mack DE, Wilson PM, Gilmore JC, Gunnell KE. Leisure-time physical activity in Canadians living with Crohn disease and ulcerative colitis: populationbased estimates. Gastroenterol Nurs. 2011;34(4):288-94.

25. van der Valk ME, Mangen M-JJ, Severs M, van der Have M, Dijkstra G, van Bodegraven AA, Fidder HH, De Jong DJ, van der Woude CJ, RombergCamps MJ: Evolution of costs of inflammatory bowel disease over two years of follow-up. PLoS One 2016, 11(4):e0142481.

26. Mehta F. Report: economic implications of inflammatory bowel disease and its management. Am J Manag Care. 2016;22(3 Suppl):551-60.
27. Burisch J, Jess T, Martinato M, Lakatos PL, EpiCom E: The burden of inflammatory bowel disease in Europe. J Crohn's Colitis 2013, 7(4):322-337.

28. Walsh AJ, Bryant RV, Travis SP. Current best practice for disease activity assessment in IBD. Nat Rev Gastroenterol Hepatol. 2016;13(10):567.

29. Pedersen BK, Saltin B. Exercise as medicine-evidence for prescribing exercise as therapy in 26 different chronic diseases. Scand J Med Sci Sports. 2015;25:1-72

30. Ng V, Millard W, Lebrun C, Howard J. Low-intensity exercise improves quality of life in patients with Crohn's disease. Clin J Sport Med. 2007;17(5):384-8.

31. Group OLoEW: "The Oxford 2011 Levels of Evidence." Oxford Centre for Evidence-Based Medicine. https://www.cebm.net/2016/05/ocebm-levels-ofevidence/? o= 56532011.

32. Moher D, Liberati A, Tetzlaff J, Altman DG, Group P: Preferred reporting items for systematic reviews and meta-analyses: the PRISMA statement. PLoS Med 2009, 6(7):e1000097.

33. Robinson RJ, Krzywicki T, Almond L, Al-Azzawi F, Abrams K, lqbal SJ, Mayberry JF. Effect of a low-impact exercise program on bone mineral density in Crohn's disease: a randomized controlled trial. Gastroenterol. 1998:115(1):36-41.

34. Elsenbruch S, Langhorst J, Popkirowa K, Müller T, Luedtke R, Franken U, Paul A, Spahn G, Michalsen A, Janssen OE. Effects of mind-body therapy on quality of life and neuroendocrine and cellular immune functions in patients with ulcerative colitis. Psychother Psychosom. 2005;74(5):277-87.

35. Cramer H, Schäfer M, Schöls M, Köcke J, Elsenbruch S, Lauche R, Egler H, Dobos G, Langhorst J, Linck G. Randomized Clinical Trial: Yoga vs. Written Self-Care Advice for Ulcerative Colitis. Deutsche Zeitschrift für Akupunktur. 2017;60(3):25-6.

36. Gerbarg PL, Jacob VE, Stevens L, Bosworth BP, Chabouni F, DeFilippis EM, Warren $R$, Trivellas M, Patel PV, Webb CD. The effect of breathing, movement, and meditation on psychological and physical symptoms and inflammatory biomarkers in inflammatory bowel disease: a randomized controlled trial. Inflamm Bowel Dis. 2015;21(12):2886-96.

37. Klare P, Nigg J, Nold J, Haller B, Krug AB, Mair S, Thoeringer CK, Christle JW, Schmid RM, Halle M. The impact of a ten-week physical exercise program on health-related quality of life in patients with inflammatory bowel disease: a prospective randomized controlled trial. Digestion. 2015;91(3):239-47.

38. D'inca R, Varnier M, Mestriner C, Martines D, D'Odorico A, Sturniolo G. Effect of moderate exercise on Crohn's disease patients in remission. Ital J Gastroenterol Hepatol. 1999;31(3):205-10.

39. Loudon CP, Corroll V, Butcher J, Rawsthorne P, Bernstein CN. The effects of physical exercise on patients with Crohn's disease. Am J Gastroenterol. 1999;94(3):697-703.

40. Candow DG, Rizci A, Chilibeck PD, Worobetz L. Effect of resistance training on Crohn's disease. Can J Appl Physiol. 2002;27:S7-8.

41. Gupta N, Khera S, Vempati R, Sharma R, Bijlani R. Effect of yoga based lifestyle intervention on state and trait anxiety. Indian J Physiol Pharmacol. 2006;50(1):41.

42. de Souza Tajiri GJ, de Castro CLN, Zaltman C. Progressive resistance training improves muscle strength in women with inflammatory bowel disease and quadriceps weakness. J Crohn's Colitis. 2014;8(12):1749-50.

43. Hassid B, Lamere B, Kattah M, Mahadevan U. Effect of intense exercise on inflammatory bowel disease activity. Am J Gastroenterol. 2016;111.

44. Fiuza-Luces C, Delmiro A, Soares-Miranda L, González-Murillo Á, MartínezPalacios J, Ramírez M, Lucia A, Morán M. Exercise training can induce cardiac autophagy at end-stage chronic conditions: Insights from a graftversus-host-disease mouse model. Brain Behav Immun. 2014;39:56-60.

45. Pedersen BK. Anti-inflammatory effects of exercise: role in diabetes and cardiovascular disease. Eur J Clin Invest. 2017;47(8):600-11.

46. Saxena A, Fletcher E, Larsen B, Baliga MS, Durstine JL, Fayad R. Effect of exercise on chemically-induced colitis in adiponectin deficient mice. J Inflamm. 2012;9(1):30.

47. Packer N, Hoffman-Goetz L. Exercise training reduces inflammatory mediators in the intestinal tract of healthy older adult mice. Canadian Journal on Aging/La Revue canadienne du vieillissement. 2012;31(2):161-71.

48. Córdova C, Lopes-e-Silva F Jr, Pires AS, Souza VC, Brito CJ, Moraes CF, Sposito AC, Nóbrega OT. Long-term resistance training is associated with reduced circulating levels of IL-6, IFN-gamma and TNF-alpha in elderly women. Neuroimmunomodulation. 2011;18(3):165-70.

49. Sloan RP, Shapiro PA, De Meersman RE, McKinley PS, Tracey K, Slavov I, Fang Y, Flood PD. Aerobic exercise attenuates inducible TNF production in humans. J App Physiol. 2007. 
50. Levin AD, Wildenberg ME, van den Brink GR: Mechanism of action of antiTNF therapy in inflammatory bowel disease. J Crohn's Colitis 2016, 10(8): 989-997.

51. Múzes G, Molnár B, Tulassay Z, Sipos F. Changes of the cytokine profile in inflammatory bowel diseases. World J Gastroenterol. 2012;18(41):5848.

52. Schmitz KH, Courneya KS, Matthews C, Demark-Wahnefried W, Galvão DA, Pinto BM, Irwin ML, Wolin KY, Segal RJ, Lucia A. American College of Sports Medicine roundtable on exercise guidelines for cancer survivors. Med Sci Sports Exerc. 2010;42(7):1409-26.

53. Pedersen B, Steensberg A, Fischer C, Keller C, Keller P, Plomgaard P, WolskPetersen E, Febbraio M. The metabolic role of IL-6 produced during exercise: is IL-6 an exercise factor? Proc Nutr Soc. 2004;63(2):263-7.

54. Ploeger HE, Takken T, Wilk B, Issenman RM, Sears R, Suri S, Timmons BW. Exercise capacity in pediatric patients with inflammatory bowel disease. J Pediatr. 2011;158(5):814-9.

55. Phillips CM, Dillon CB, Perry IJ. Does replacing sedentary behaviour with light or moderate to vigorous physical activity modulate inflammatory status in adults? Int J Behav Nutr Phys Act. 2017;14(1):138.

56. Zhao G, Zhou S, Davie A, Su Q. Effects of moderate and high intensity exercise on T1/T2 balance. Exercise immunology review. 2012:18.

57. Hashash JG, Binion DG. Exercise and Inflammatory Bowel Disease Insights into Etiopathogenesis and Modification of Clinical Course. Gastroenterol Clin. 2017:46(4):895-905

58. Visser M, Pahor M, Taaffe DR, Goodpaster BH, Simonsick EM, Newman AB, Nevitt M, Harris TB. Relationship of interleukin- 6 and tumor necrosis factor-a with muscle mass and muscle strength in elderly men and women: the Health ABC Study. J Gerontol A Biol Sci Med Sci. 2002;57(5):M326-32.

59. Späte U, Schulze PC. Proinflammatory cytokines and skeletal muscle. Curr Opin Clin Nutr Metab Care. 2004;7(3):265-9.

60. Scaldaferri F, Pizzoferrato M, Lopetuso LR, Musca T, Ingravalle F, Sicignano LL, Mentella M, Miggiano G, Mele MC, Gaetani E. Nutrition and IBD: malnutrition and/or sarcopenia? A practical guide. Gastroenterol Res Pract. 2017;2017.

61. Schaper L, Hengstermann S, Körnicke T, Büning C, Pirlich M, WinklhoferRoob B, Lochs H, Valentini L: Sarkopenie mit verminderter Muskelfunktion bei Patienten mit chronisch entzündlichen Darmerkrankungen (CED) in Remission. Zeitschrift für Gastroenterologie 2007, 45(08):P094.

62. Harber MP, Kaminsky LA, Arena R, Blair SN, Franklin BA, Myers J, Ross R. Impact of cardiorespiratory fitness on all-cause and disease-specific mortality: advances since 2009. Prog Cardiovasc Dis. 2017;60(1):11-20.

63. Barsevick AM, Cleeland CS, Manning DC, O'Mara AM, Reeve BB, Scott JA, Sloan JA. ASCPRO recommendations for the assessment of fatigue as an outcome in clinical trials. J Pain Symptom Manage. 2010;39(6): 1086-99.

64. Grimstad T, Norheim KB, Isaksen K, Leitao K, Hetta AK, Carlsen A, Karlsen LN, Skoie IM, Gøransson L, Harboe E. Fatigue in newly diagnosed inflammatory bowel disease. Crohn's Colitis. 2015;9(9):725-30.

65. Borren NZ, van der Woude CJ, Ananthakrishnan AN. Fatigue in IBD: epidemiology, pathophysiology and management. Nat Rev Gastroenterol Hepatol. 2018;1.

66. Larun L, Brurberg KG, Odgaard-Jensen J, Price JR. Exercise therapy for chronic fatigue syndrome. Cochrane Database Syst Rev. (2016, 2).

67. Nathan I, Norton C, Czuber-Dochan W, Forbes A. Exercise in individuals with inflammatory bowel disease. Gastroenterol Nurs. 2013;36(6):437-42.

68. Vogelaar L, Van den Berg-Emons R, Bussmann H, Rozenberg R, Timman R, Van der Woude CJ. Physical fitness and physical activity in fatigued and non-fatigued inflammatory bowel disease patients. Scand J Gastroenterol. 2015;50(11):1357-67.

69. Bower JE, Ganz PA, Aziz N, Fahey JL. Fatigue and proinflammatory cytokine activity in breast cancer survivors. Psychosom Med. 2002;64(4):604-11.

70. Collado-Hidalgo A, Bower JE, Ganz PA, Cole SW, Irwin MR. Inflammatory biomarkers for persistent fatigue in breast cancer survivors. Clin Cancer Res. 2006;12(9):2759-66.

71. van Weert E, Hoekstra-Weebers J, Otter R, Postema K, Sanderman R, van der Schans C. Cancer-related fatigue: predictors and effects of rehabilitation. Oncologist. 2006;11(2):184-96.

72. Wahed M, Goodhand J, Langmead L, Irving PM, Sanderson J, Bloom S, McCartney S, Mawdsley J, Rampton DS. Anxiety and psychological stress in acute severe ulcerative colitis: prevalence and effect on outcome. Gut. 2011; 60(Suppl 1):A222.
73. Stonerock GL, Hoffman BM, Smith PJ, Blumenthal JA. Exercise as treatment for anxiety: systematic review and analysis. Ann Behav Med. 2015;49(4):542-56.

74. Anderson EH, Shivakumar G. Effects of exercise and physical activity on anxiety. Front Psych. 2013:4:27.

75. Infurna FJ, Gerstorf D. Perceived control relates to better functional health and lower cardio-metabolic risk: The mediating role of physical activity. Health Psychol. 2014;33(1):85.

76. Nafradi L, Nakamoto K, Schulz PJ. Is patient empowerment the key to promote adherence? A systematic review of the relationship between selfefficacy, health locus of control and medication adherence. PloS one. 2017; 12(10):e0186458.

77. van der Have M, van der Alst KS, Kaptein AA, Leenders M, Siersma PD, Oldenburg B, et al. Determinants of health-related quality of life in Crohn's disease: A systematic review and meta-analysis. J Crohn's Colitis. 2014,8:93-106.

78. Anyoka NK, Trueman P, Green C, Pavey TG, Taylor RS. Physical activity and health related quality of life. BMC Public Health. 2012;12:624-31.

79. Buffart LM, Kalter J, Sweegers MG, Courneya KS, Newton RU, Aaronson NK, Jacobsen PB, May AM, Galvão DA, Chinapaw MJ. Effects and moderators of exercise on quality of life and physical function in patients with cancer: an individual patient data meta-analysis of 34 RCTs. Cancer Treatment Rev. 2017:52:91-104

80. Cai H, Li G, Zhang P, Xu D, Chen L. Effect of exercise on the quality of life in type 2 diabetes mellitus: a systematic review. Qual Life Res. 2017;26(3):515-30.

81. Taylor K, Scuggs PW, Balemba OB, Wiest MW, Vella CA. Associations between physical activity, resilience, and quality of life in people with inflammatory bowel disease. Eur J Appl Physiol. 2018;118:829-36.

82. Bilski J, Brzozowski B, Mazur-Bialy A, Sliwowski Z, Brzozowski T. The role of physical exercise in inflammatory bowel disease. BioMed Res Int. 2014;2014.

83. Sudeck G, Pfeifer K. Physical activity-related health competence as an integrative objective in exercise therapy and health sports-conception and validation of a short questionnaire. Sportwissenschaft. 2016;46(2):74-87.

84. Sachar DB, BTFot IOIBD. Role of Biomarkers in the Study and Management of Inflammatory Bowel Disease: A "Nonsystematic" Review. Inflammat Bowel Dis. 2014;20(12):2511-8.

85. Duan N, Kravitz RL, Schmid CH. Single-patient (n-of-1) trials: a pragmatic clinical decision methodology for patient-centered comparative effectiveness research. J Clin Epidemiol. 2013;66(8):S21-8.

\section{Publisher's Note}

Springer Nature remains neutral with regard to jurisdictional claims in published maps and institutional affiliations.

Ready to submit your research? Choose BMC and benefit from:

- fast, convenient online submission

- thorough peer review by experienced researchers in your field

- rapid publication on acceptance

- support for research data, including large and complex data types

- gold Open Access which fosters wider collaboration and increased citations

- maximum visibility for your research: over $100 \mathrm{M}$ website views per year

At $\mathrm{BMC}$, research is always in progress.

Learn more biomedcentral.com/submissions 